\title{
Applications for virtual reality experiences in tertiary education
}

\author{
Ghaith Zakaria and Sonia Wilkie \\ Victoria University
}

Providing authentic learning experiences is a stellar teaching and learning strategy to prepare students for their future careers. They cultivate and enhance students learning by providing hands- on, experiential learning opportunities. However, incorporating such activities can be challenging, logistically complicated and may encapsulate hazardous situations and safety concerns. When these challenges arise, Virtual and Augmented Reality can offer learning experiences to supplement the curriculum, and optimise the valuable time spent on location. This paper provides an overview of different pedagogical applications to incorporate virtual experiences, namely Virtual experiences to supplement and optimise real-world experiences; Simulations and virtual tours for inaccessible or remote locations; First-person point-of-view; and Virtual scenarios for dangerous situations, which is supported with examples of activities used in higher education.

Keywords: Virtual Reality; Virtual Tours; Simulations; Authentic Learning, Pedagogy

\section{Introduction}

Experiential learning activities are an important teaching and learning strategy which provides students with authentic learning opportunities that prepares them for their future careers. Ways that universities incorporate experiential learning opportunities include: embarking on field trips, site visits, and tours of key locations; working in laboratories or workshops using specialised equipment and tools; providing hands-on access to restricted resources such as specimens (anatomical, biological, botanical, geological); or gaining experience working with clients in customer-service and clinical environments. These activities enhance students learning, cultivate critical thinking, problem-solving, and practical skills by providing authentic learning opportunities for situations they will encounter in their future careers.

However, incorporating such activities can be challenging, cost-prohibitive, logistically complicated, and may involve hazardous situations or safety concerns when undertaken. Furthermore, the implications of COVID19 working from home orders or home isolation mean that students cannot physically participate in on-campus classes or location-based learning experiences. When these challenges arise, virtual experiences can offer authentic learning scenarios to supplement, or occasionally replace activities in the curriculum (Zhao et al., 2020).

Virtual and Augmented Reality (VR/AR) are two technologies increasingly utilised as an effective learning resource and activity in Higher Education. Bespoke virtual tours (such as the tour of Victoria University's Innovation Space 'The Hive' in Figure 4) can be created from spherical content ( $360^{\circ}$ video or images) at a relatively low cost, and can be embedded into an LMS (Wilkie, et al., 2018; Zakaria et al., 2019, 2020) requiring minimal digital literacy, graphical design, and coding skills.

Evidence shows that virtual experiences enhance learning by presenting students with immersive experiences that model real-world situations and tasks they'll perform in their future careers, whilst introducing a novel approach to delivering content and scenarios. As noted by Chen and Fragomeni (2018), VR/AR technologies offer an opportunity to provide learning experiences that cater to a broad spectrum of learners. Furthermore, these technologies can create a more engaging learning environment and enhance learners' motivation and interaction with the content delivered (Bacca et al., 2014; McDonald et al., 2018). 
In this overview we identify four categories of pedagogical use for virtual experiences, namely Virtual experiences to supplement and optimise real-world experiences; Simulations and virtual tours for inaccessible or remote locations; First-person point-of-view; and Virtual scenarios for dangerous situations; And present examples where the creation of virtual experiences and their pedagogical applications provided solutions that enhanced the student learning experience in tertiary and adult education.

\section{Virtual experiences to supplement and optimise real experiences}

Real-world learning experiences are the penultimate authentic learning activity. They provide opportunities for students to physically immerse-in and experience the work environment; to observe and practically apply theoretical knowledge and skills; and to communicate with experts currently working in the field. These experiences prepare, and equip students with the skills, knowledge, and expectations to succeed in the workplace. However, incorporating such real-world learning experiences into the curriculum can present many challenges. Visiting manufacturing facilities, construction sites, industry partners and environmental locations often requires authorised approval and time spent on location is limited. Similarly, laboratories, workshops and clinical environments are limited by the number of people they can accommodate, they are often in high demand by competing courses, and it can be difficult to obtain specimens, resources, or equipment (AbouHashem et al., 2015). When obtained, the time spent on-location is valuable and limited. Therefore, it is imperative to optimise the time spent on-location, maximising student learning and experience (Seifan et al., 2019). Creating virtual experiences as an activity for students to undertake before embarking on the real experience can help prepare students in advance, and optimise the time spent on location.

One such example is providing students with an online health and safety module (Figures $1 \& 2$ ) before undertaking a laboratory, workshop, or clinical placement. Students become familiar with the space, visually see the room layout and location of equipment; gain insight on workplace procedures and policies which need to be followed; undertake health and safety training; and advise students of any PPE or equipment they need to purchase before entering and using the facilities.

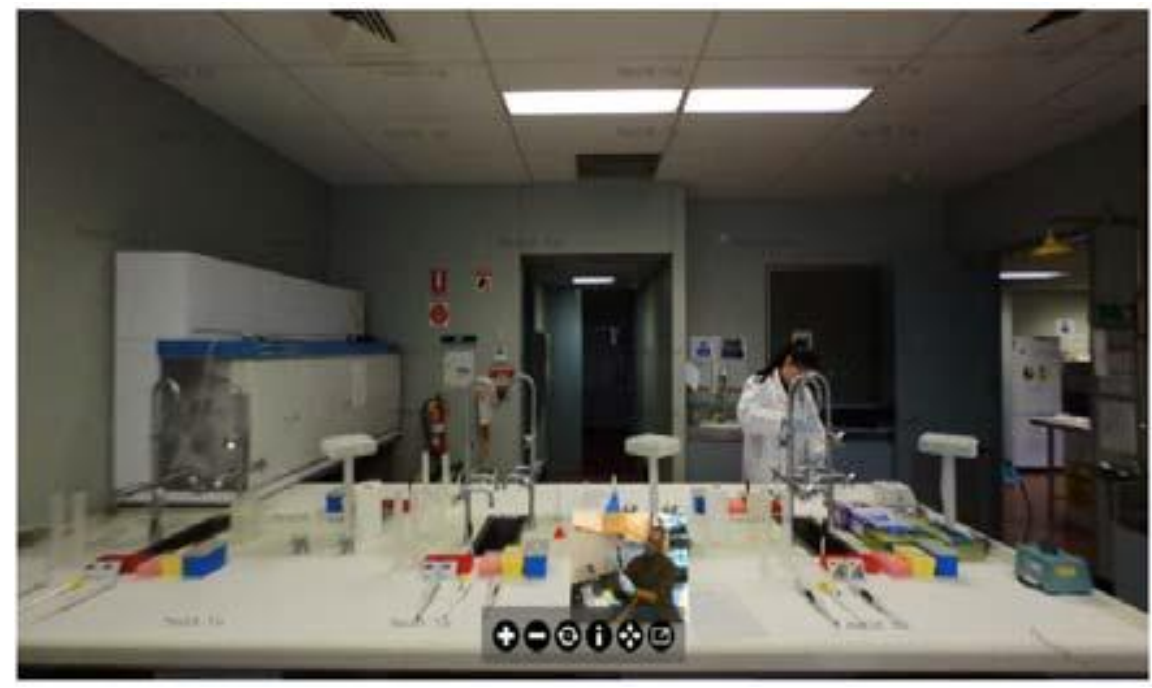

Figure $1.360^{\circ}$ Virtual tour of laboratory with hotspot interactivity revealing further information 


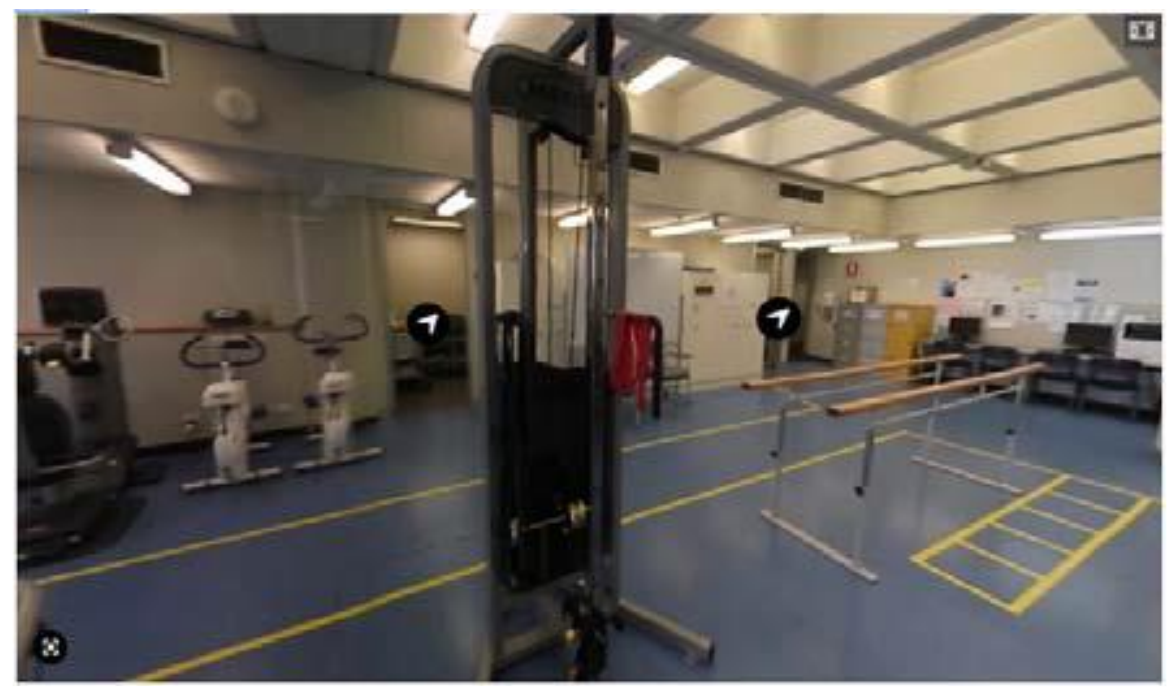

Figure $2.360^{\circ}$ Virtual tour of VUCR rehabilitation clinic at Victoria University

Another often used virtual experience is a virtual tour of geographical locations, cities, buildings (Figure 3) or key sites, which students view before going on-location. The activity may consist of simply exploring google maps in street-view, or developing bespoke spherical content $\left(360^{\circ}\right.$ video, image or simulation) of the site. These activities enable students to see the different geographical features of the location, navigate through the environment, explore changing features or conditions, and establish directions, in preparation before going onsite. This enables students to adequately prepare for site conditions, think about situations they will encounter, questions they may have, problems that may arise, and tasks they can perform on location; reducing any unexpected circumstances that may arise on location. These virtual experiences are particularly useful in the disciplines of engineering, construction, architecture, earth sciences, geography, and outdoor education.

To demonstrate the activity's benefits, Seifan et al. (2019) created a virtual field trip for Engineering students to undertake before visiting a wastewater treatment plant, as a method to promote student's industrial insight and knowledge about wastewater treatment, before going on-location. They found that the Virtual Field Trips (VFT) are a "powerful supplement to Real Field Trip (RFT) as it provides the necessary pre-knowledge to students in a way that maximised learning during the RFT". The virtual experience again proved useful to the students after participating in the field trip, as a point of reference. It enabled the students to review the location, experience, and to remind themselves of layouts, equipment, and key processes. Seifan et al. (2019) also measured student preference and enthusiasm for the virtual and real field trips, finding that three-quarters of the participants found the VFT enhanced their understanding of the lab results and made the writing of their final report a lot easier.

\section{Simulations and virtual tours for inaccessible or remote locations}

Simulations and virtual tours offer an excellent opportunity for students to immerse themselves into places which are not physically accessible.

COVID19 working from home orders and home isolation has rapidly forced many universities into remote teaching. Restrictions mean that even students local to the university may not have access to campus facilities, be able to visit key locations, or participate in location-based learning experiences. In these circumstances, a simulation or virtual tour (Figure 4) can provide learning experiences, whilst not optimal, but fit-for-purpose when they otherwise would not occur. These virtual experiences, combined with remote teaching, means that students can undertake study from any location, including interstate and international distances. Furthermore, it provides students with great flexibility, they can immerse themselves in the virtual environment at a time and place that is convenient to them; and can revisit the learning experience as often as they choose to. 

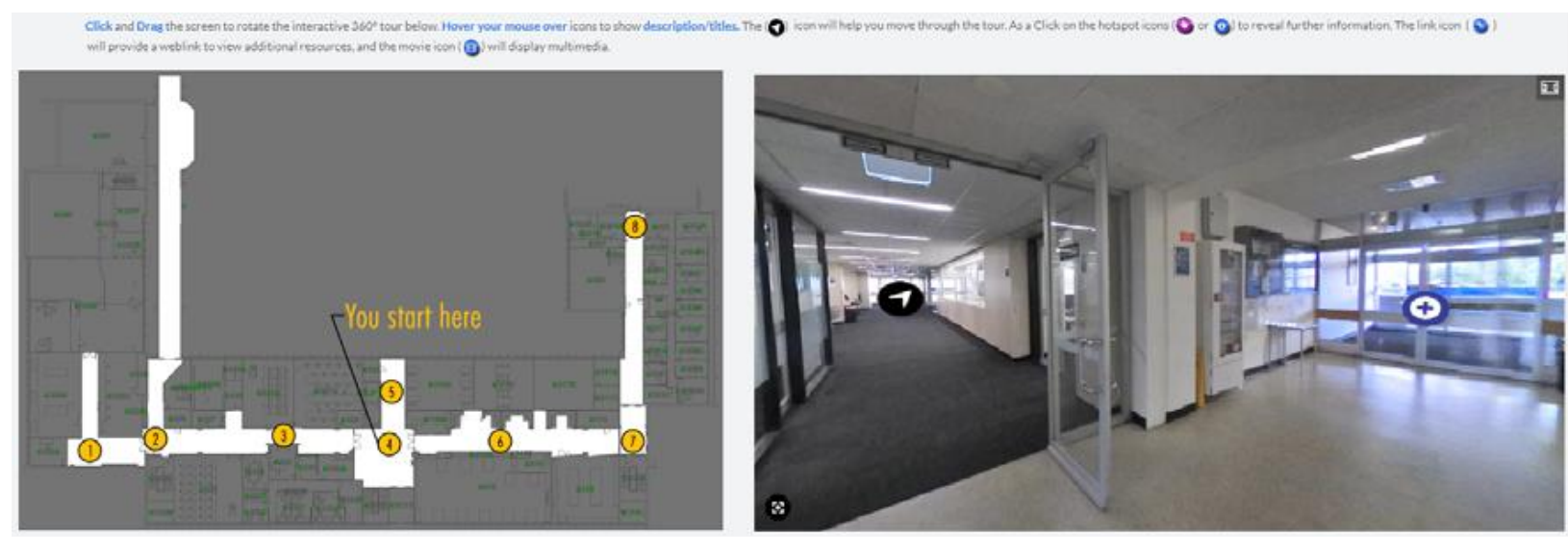

Figure 3. $360^{\circ}$ Virtual tour of the D building at Victoria University to prompt students memory of the location, its layout, and materials used for construction, when they are not on campus.

Additionally, students can be provided with (virtual) tours of leading international scientific laboratories (such as Large Hadron Collider), world heritage sites, international museums, and art galleries, that access was previously limited by distance. Many important sites may also not be physically accessible due to policies and regulations which require high-level authorisation. This is particularly the case with regards to STEM disciplines, with many sites restricted due to safety and logistical constraints (Ijaz et al., 2017).

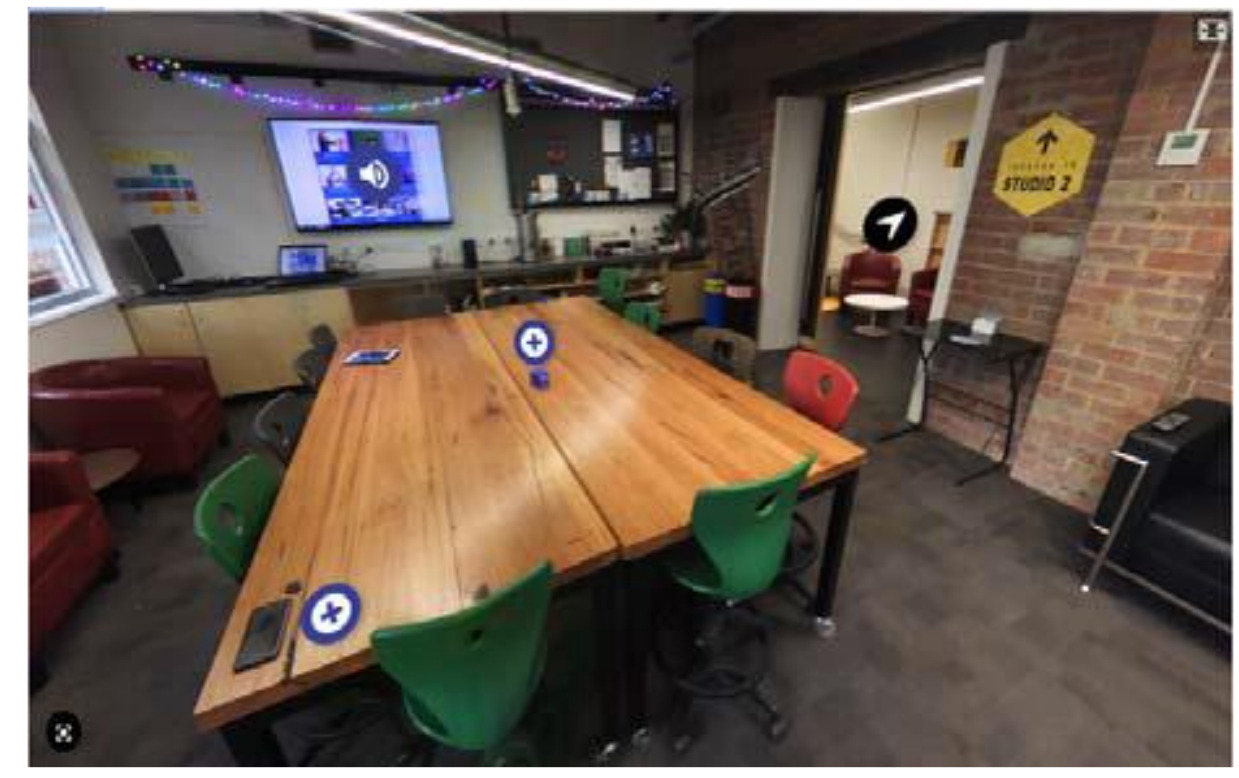

Figure 4. $360^{\circ}$ Virtual Tour of 'The Hive' Victoria University's innovation, collaboration \& cocreation Space 


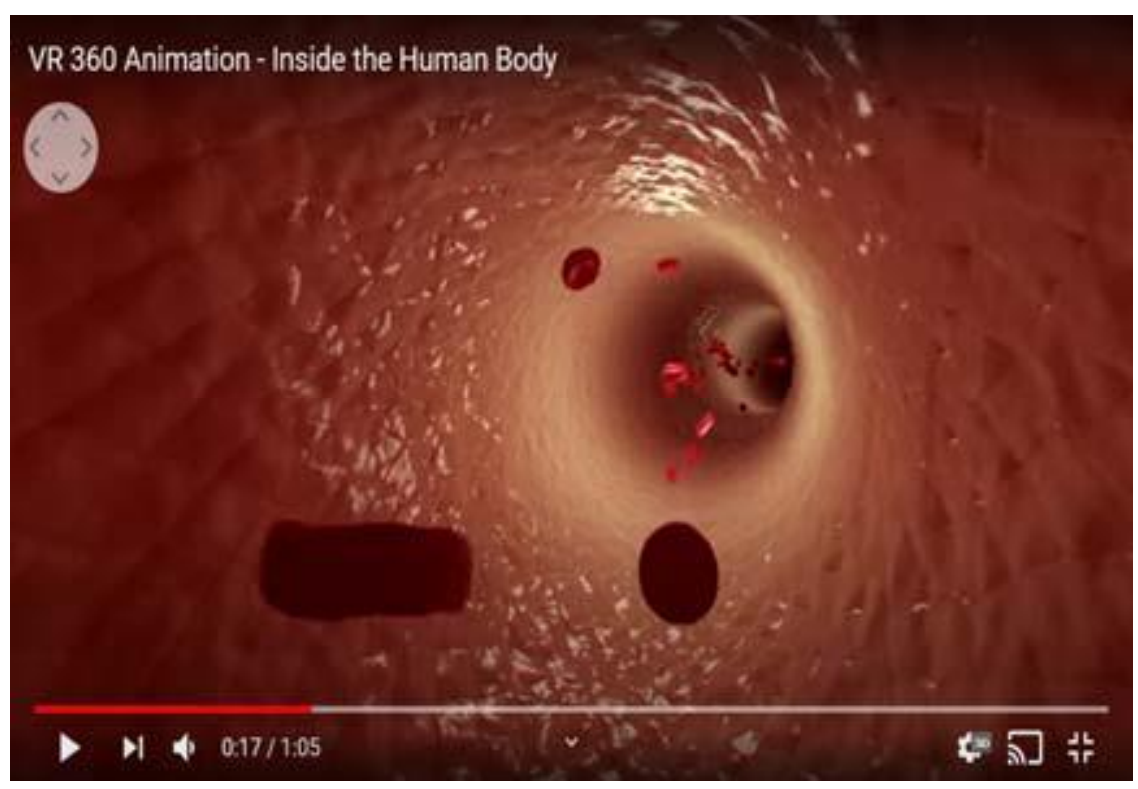

Figure $5.360^{\circ}$ tour inside the vascular system https://youtu.be/j__lspv3n7j]A

Simulations and virtual tours are also beneficial for observing and immersing-in microscopic elements such as chemical molecules, or inaccessible anatomical locations such as organs or tissues inside the human body (Kaddour et al., 2020). Students can observe brain neural activity, or navigate around simulations of a beating heart and vascular system (Figure 5). Similarly, Science students can observe an experiment from many angles, when in reality they would need to observe from a safe distance due to the dangerous nature of the observation.

\section{First-Person Point-of-view}

The First-Person Point-of-view places the viewer in the position of the person performing the task or action. This provides students with a unique perspective which is not possible in a traditional classroom observation of the teacher or professional performing a demonstration. By providing the view of the person performing the task, all students have the best seat in the house, in addition to technical advantages of being able to pause, replay or fast forward the demonstration.

Capturing the material in $360^{\circ}$ format where multiple events are co-occurring provides ideal simulation for people gaining experience in supervising situations that require keen spatial orientation skills. Early adopters of this training technology was the Air Force and airline industries, developing flight simulators to enable pilots to practice their spatial orientation skills and piloting precision before embarking on high-risk real flights (Koglbauer, 2016; Myers et al., 2018; Safi et al., 2019).

In the field of education, pre-service teachers develop their 'professional vision'- learning how to supervise a classroom of students with competing priorities, noticing and interpreting different classroom events, ensuring individuals are participating in activities, answering any questions that arise around the room, and manage the behaviour and emotions of an entire room of students. Theelen et al. (2019) and Windscheid et al. (2018) demonstrate that by developing $360^{\circ}$ immersive experiences of classroom scenarios, helped reduce 'practice shock' experienced by the pre-service teachers when they first went on placement, and bridged the gap between theoretical concepts learnt at university, and applying them in practice to a dynamic classroom of students.

A similar example exists in the discipline of sports coaching, whereby coaches observe multiple athletes performing different movements during training or competition, and need to make rapid decisions and provide feedback on an individual's technique and performance. Farley et al. (2019) and Sanger et al. (2019) found that $360^{\circ}$ cameras placed on a coach or athlete's head, provided students with an important tool to develop quick, decision-making and 
assessment skills, by placing the students in the position of the coach or athlete.

\section{Virtual scenarios for dangerous situations}

Many careers involve people working in dangerous workplace situations. Professions with known occupational hazards include the emergency services, military, manufacturing, engineering, construction, mining, and agriculture. VR training programs and simulations provide a solution to exposing and training people to these high-risk and high-pressure scenarios so students can build resilience, establish clear thinking and control emotions, and are prepared when encountered in the workplace.

When performing the task itself is risky, not only does it have to be performed correctly, but a wrong decision / action, or a delay to the decision / action, can impact the outcome. Furthermore, these situations are often highpressure and emotions need to be controlled. VR's immersive qualities and ability to create presence (Slater 2009) and embodiment (Johnson-Glenberg 2018) of another person or environment create the ideal learning activity to bridge the gap between theoretical knowledge learnt in the classroom, and application in the workplace, with the activities providing "students with a safe and repeatable environment to practise key techniques" Jeong et al. (2019). This is critical for tasks which involve life or death decisions and consequences.

One such example is risk identification activity, whereby students identify possible risks and hazards in a given situation, safely from their classroom. The snakebite prevention and first-aid training VR simulation developed by McMillan and Horan (2019) whereby trainee's identify locations that snakes may be encountered. Once bitten by a virtual snake trainee's then undertake first-aid training, apply a pressure bandage, and scanning the bandaged area, usually an arm or leg. Biometric sensors in the bandage inform the trainee if they have correctly applied the correct pressure and trainee's are rated on their success (Smilevski, et al., 2018).

In addition to industries where occupational hazards are explicit, many less-recognised workplace dangers exist which new employees do not expect and are often ill-prepared with little training. Workplace conflict occurs in many occupations with many new employees not expecting the situations they encounter. Occupations that regularly experience verbal abuse and physical assault include customer services, hospitality, and healthcare. In these highpressure situations, people need to remain calm, control their stress levels, manage conflict and draw on deescalation techniques. Practicing these skills builds students resilience, confidence, and success.

Recognising the need for specialised training in the field of nursing, the University of Newcastle developed the conflict resolution VR simulation 'Angry Stan' (Johnston, 2019; Vukovic, 2019) which is based on real-world scenarios that nurses encounter on a regular basis. Hazelton (Johnston 2019) states that "it was imperative to develop an immersive training program where students can practise dealing with these potential situations in a safe, repeatable and realistic environment". In the simulation Stan attends the hospital and becomes increasingly agitated. Students practice their de-escalation techniques, and the calmer their response, the easier Stan is to deal with. However, even if students provides non-provocative responses, if their biofeedback (heartrate and stress levels) increase, so does Stans response. Pento (Johnston 2019) highlights that "The days of teaching en masse are behind us. The qualitative and quantitative responses to the program actually help us learn from the students so we can tailor education to individuals, ensuring a deeper teaching and learning experience". This means that the scenario and training is personalised to the individual student and their informational needs.

\section{Discussion}

The examples of virtual learning experiences provided in this overview demonstrate that whilst providing a novel learning experience, they also pedagogically enhance student learning in higher education. The virtual experiences can supplement the curriculum by bridging the gap between theoretical knowledge and practical application; optimise the time and success of real location-based learning experiences; create a safe space for students to make mistakes and to learn from them, without real consequences; and provide authentic learning experiences that would otherwise be limited or not possible. 


\section{Acknowledgements}

Thanks to Dr. Malindu Sandanayake, Achini Peiris, Dr. George Elias, Dr. Mary Woessner, Academic staff, and the Connected Learning Team at Victoria University,

\section{References}

AbouHashem, Y., Dayal, M., Savanah, S., \& Strkalj, G. (2015). The application of 3D printing in anatomy education. Medical Education Online, 20 (1), 29847.

Bacca, J., Baldiris, S., Fabregat, R., Graf, S. (2014). Augmented reality trends in education: a systematic review of research \& applications.

Chen, J. Y., \& Fragomeni, G. (Eds.). (2018). Virtual, augmented and mixed reality: interaction, navigation, visualization, embodiment, and simulation, 10th International Conference, VAMR 2018, held with HCI International 2018, Las Vegas, USA, (vol. 10909) Springer.

Chen, L., Gibbons, J., Trifkovic, A., Zakaria, G., \& Wilkie, S. (2019). New technology is the way ahead: Technology in sport and education. Inspire, Explore, and Create Symposium, Victoria University, Melbourne, Australia.

Farley, O. R., Spencer, K., \& Baudinet, L. (2019). Virtual reality in sports coaching, skill acquisition and application to surfing: A review.

Ijaz, K., Marks, B., Hartley, T., Gibbens, P., \& Thomas, J. (2017). The immersive learning laboratory: employing virtual reality technology in teaching. In 28th Annual Conference of the Australasian Association for Engineering Education (AAEE 2017) (p. 974).

Johnston, M. IT News. 4 Dec, 2019.https://www.itnews.com.au/news/newcastle-uni-taps-biofeedback-in-vrconflict-training-534860

Johnson-Glenberg, M. C. (2018). Immersive VR and education: Embodied design principles that include gesture and hand controls. Frontiers in Robotics and AI, 5, 81.

Jeong, S. Y. S., \& Lee, K. O. (2019). The emergence of virtual reality simulation and its implications for nursing profession. Korean Journal of Women Health Nursing, 25(2), 125-128.

Kaddour Z., Derrar S.D., \& Malti A. (2020). VRAnat: A complete virtual reality platform for academic training in anatomy. In: Ezziyyani M. (eds) Advances in intelligent systems and computing, vol 1103. Springer, Cham.

Koglbauer, I. (2016). Simulator training improves pilots' procedural memory and generalisation of behavior in critical flight situations. Cognitie, Creier, Comportament/Cognition, Brain, Behavior, 20(5).

McDonald, T., Zakaria, G., Wilkie, S., \& (2018). H5P online interactive activities provide an alternative to lectures. The 43rd International Conference on Improving University Teaching (IUT). Port Macquarie, Australia

McMillan, S., \& Horan, B. (29 Jan, 2019). The future is now: Virtual Reality becomes actual reality at Melbourne Water. https:/www.melbournewater.com.au/water-data-and-education/news/future-now-virtual-reality-becomesactual-reality-melbourne-water

Myers III, P. L., Starr, A. W., \& Mullins, K. (2018). Flight simulator fidelity, training transfer, and the role of instructors in optimising learning. International Journal of Aviation, Aeronautics, and Aerospace, 5(1), 6.

Safi, Chung, J, \& Pradhan, P. (2019). Review of augmented reality in aerospace industry. Aircraft Engineering \& Aerospace Technology.

Sanger, M. A., Buns, M. T., \& Thomas, K. T. (2019). The Effect of Virtual Training on Speed and Accuracy of Decision Making in Sport. Journal of Human Kinetics, 70(1), 261-273. https://doi.org/10.2478/hukin-2019-0041

Seifan, M., Dada, D., \& Berenjian, A. (2019). The effect of virtual field trip as an introductory tool for an engineering real field trip. Education for Chemical Engineers, 27, 6-11. DOI: https://doi.org/10.1016/j.ece.2018.11.005

Slater, M., Lotto, B., Arnold, M. M., \& Sánchez-Vives, M. V. (2009). How we experience immersive virtual environments: the concept of presence and its measurement. Anuario de Psicología, 2009, vol. 40, p. $193-210$.

Smilevski, S., Thirunavukkarasu, G, Seyedmahmoudian, M., McMillan, S., \& Horan, B. (2018). Mixed reality tool for training on pressure immobilization treatment of snake bite envenomation. In Proceedings of the 23rd ACM Conference on 3D Web Technology (pp. 1-7).

Theelen, H., Van den Beemt, A., \& den Brok, P. (2019). Using 360-degree videos in teacher education to improve 
pre-service teachers' professional interpersonal vision. Journal of Computer Assisted Learning, 35(5), 582-594.

Vukovic, D. ABC News. 23 Nov, 2019. https://www.abc.net.au/news/2019-11-23/angry-stan-virtual-realitytechnology/11690360.

Wilkie, S., Zakaria, G., McDonald, T., \& Borland, R. (2018). Considerations for designing H5P online interactive activities. Open Oceans: Learning without borders. Proceedings ASCILITE, 543-549.

Windscheid, J., \& Will, A. (2018). A web-based multi-screen $360^{\circ}$ video player for pre-service teacher training. Universitätsbibliothek.

Zakaria, G. \& Wilkie, S. (2020). Virtual Reality and Augmented Reality Experiences To Engage Students' Learning Remotely. The $45^{\text {th }}$ International Conference on Improving University Teaching (IUT), Padua, Italy.

Zakaria, G., \& Wilkie, S. (2018). Technology in Tertiary Education - Exercise Science. Inspire, Explore, and Create Symposium, Victoria University, Melbourne, Australia.

Zakaria, G., \& Wilkie, S. (2019). Virtual Scientific Tours of Environmental Locations. In Proceedings of The Higher Education Technology Agenda (THETA) 2019 International Conference, Wollongong, Australia, 2019. DOI: 10.13140/RG.2.2.13782.40001.

Zhao, J., LaFemina, P., Carr, J., Sajjadi, P., Wallgrün, J. O., \& Klippel, A. (2020). Learning in the field: Comparison of desktop, immersive virtual reality, and actual field trips for place-based STEM education. In IEEE Conference on Virtual Reality \& 3D User Interfaces.

Zakaria, G. \& Wilkie, S. (2020). Applications for Virtual Reality Experiences in Tertiary Education. In S. Gregory, S. Warburton, \& M. Parkes (Eds.), ASCILITE's First Virtual Conference. Proceedings ASCILITE 2020 in Armidale (pp. 186-193). https://doi.org/10.14742/ascilite2020.0139

Note: All published papers are refereed, having undergone a double-blind peer-review process.

The author(s) assign a Creative Commons by attribution licence enabling others to distribute, remix, tweak, and build upon their work, even commercially, as long as credit is given to the author(s) for the original creation.

(C) Zakaria, G. \& Wilkie, S. 2020 